\section{Air embolism caused by blower mister}

\section{To the Editor:}

We congratulate Nollert and colleagues ${ }^{1}$ for their courage in publishing the adverse event experienced with a blower mister while performing a central anastomosis. Especially in off-pump coronary surgery, blower misters are most frequently used for bleeding control while performing the distal anastomoses. ${ }^{2}$

Gaseous emboli caused by liberal use of the blower mister might additionally result in air locks within coronary vessels. This has been reported verbally, but published evidence is missing. Another complication was published: during performance of an anastomosis in a minimally invasive direct coronary artery bypass procedure, the ventricle was injured, and air embolism was detected with the echocardiography in the heart. $^{3}$

Air locks in the coronary circulation can lead to ischemia, decreased myocardial contractility, and possibly life-threatening cardiac arrhythmia. ${ }^{4}$ The coronary circulation remains the most difficult compartment from which to remove air bubbles. For this reason and furthermore because of the possibility of endothelial damage, we recommend caution in the use of the blower mister.

Helmut Mair, $M D$

Paul Sergeant, $M D, P h D$

Department of Cardiac Surgery

University of Leuven

Leuven, Belgium

\section{References}

1. Nollert G, Oberhoffer M, Reichart B, Vicol C. Combination of the HEARTSTRING proximal seal system with a blower mister: a possible source of gas emboli. J Thorac Cardiovasc Surg. 2003;126:1192-4.

2. Roy A, Stanbridge RL, O'Regan D, Salerno G, Saldanha C, Griselli M, et al. Progression to $100 \%$ off-pump coronary artery bypass with the Octopus 1 dual holder. Heart Surg Forum. 2000;4:174-8.

3. Karashima Y, Sha K, Iwatsubo T, Shimoda T, Horiuchi T, Kurita N, et al. Paradoxical embolism during MIDCAB surgery. Masui. 2002;51:673-5.

4. Van Blankenstein JH, Slager CJ, Schuurbiers JC, Strikwerda S, Verdouw PD. Heart function after injection of small air bubbles in coronary artery of pigs. J Appl Physiol. 1993; 75:1201-7.

\section{Quadricuspid aortic valves and anomalies of the coronary arteries To the Editor:}

Mecozzi and colleagues ${ }^{1}$ recently reported the case of a patient with severe stenosis of a quadricuspid aortic valve (QAV) requiring valve replacement. We would like to point out a pitfall that could face the surgeon during aortic valve replacement in patients with such a condition.

QAVs are a rare entity with a potential for serious complications. ${ }^{2}$ Aortic regurgitation is the most prevalent haemodynamic abnormality, often requiring aortic valve replacement. ${ }^{3}$ When considering surgical treatment, it is important to pay attention to the fact that the QAV can be associated with other congenital cardiac malformations (eg, ventricular septal defects, patent ductus arteriosus, and subaortic fibromuscular stenosis). ${ }^{3}$ Of special importance to the surgeon are anomalies of the coronary arteries, ${ }^{2}$ which are the most frequent cardiac defects associated with a QAV. ${ }^{3}$ Single coronary ostium ${ }^{4}$ and displacement of the left ${ }^{5}$ and right ${ }^{6}$ coronary orifice have all been reported in association with a QAV. From the surgical standpoint, it is important to recognize any displacement of the coronary ostia to prevent ostial obstruction of the coronary artery when fixing the prosthetic valve ring. ${ }^{7}$ Therefore the anatomy of the heart, especially that of the coronary arteries, must be carefully evaluated in patients with a QAV before surgical intervention to prevent serious complications.

Oktay Tutarel

Hannover Medical School Hannover, Germany

\section{References}

1. Mecozzi G, Pratali S, Milano A, Nardi C, Bortolotti U. Severe quadricuspid aortic valve stenosis after mediastinal irradiation. J Thorac Cardiovasc Surg. 2003;126:1198-9.

2. Tutarel $\mathrm{O}$. The quadricuspid aortic valve. Wien Klin Wochenschr. 2003;115:212.

3. Janssens U, Klues HG, Hanrath P. Congenital quadricuspid aortic valve anomaly associated with hypertrophic non-obstructive cardiomyopathy: a case report and review of the literature. Heart. 1997;78:83-7.

4. Kim HS, McBride RA, Titus JL. Quadricuspid aortic valve and single coronary ostium. Arch Pathol Lab Med. 1988;112:842-4.

5. Wyatt JP, Goldenberg H. Supernumerary aortic cusps with multiple fenestrations and with displacement of the left coronary orifice. Arch Pathol. 1948;45:784-6.

6. Lanzillo G, Breccia PA, Intonti F. Congenital quadricuspid aortic valve with displacement of the right coronary orifice. Scand J Thorac Cardiovasc Surg. 1981;15:149-51.
7. Aoyagi S, Kawara T, Yasunaga H, Kosuga K, Oishi K. Congenital quadricuspid aortic valve associated with aortic regurgitation. Thorac Cardiovasc Surg. 1992;40:225-6. doi:10.1016/j.jtcvs.2003.11.040

\section{Reply to the Editor:}

We appreciate the comments by Dr Turatel to our article on a case of quadricuspid aortic valve stenosis recently published in the Journal. ${ }^{1}$ He reminds us of the importance of other intracardiac anomalies that are frequently associated with this malformation and that must be recognized when planning an operation to avoid potentially serious complications. We fully agree that among these anomalies displacement of the coronary ostia might play an important role because in some instances it might require modification of the standard surgical technique of prosthetic valve insertion, particularly when a stentless valve is chosen as aortic valve substitute. This point was stressed in a previous publication on the same subject by our group ${ }^{2}$ when reporting on a patient with aortic insufficiency caused by a quadricuspid valve, in whom, at operation, the right coronary ostium appeared displaced downward, being very close to the commissure between the right and the accessory cusps. In the present case $^{1}$ no anomalies of the coronary arteries were found, and because of severe calcification of the ascending aorta, it was decided to simultaneously replace the aortic valve and root with a cryopreserved homograft. We believe that with such technique, which requires adequate mobilization of the coronary buttons, displacement of a coronary ostium, even if present, would not have been a problem.

$$
\begin{array}{r}
\text { Gianclaudio Mecozzi, } M D \\
\text { Stefano Pratali, } M D \\
\text { Uberto Bortolotti, } M D \\
\text { Division of Cardiac Surgery } \\
\text { Cardio Thoracic Department } \\
\text { University of Pisa Medical School } \\
\text { Pisa, Italy }
\end{array}
$$

\section{References}

1. Mecozzi G, Pratali S, Milano A, Nardi C, Bortolotti U. Severe quadricuspid aortic valve stenosis after mediastinal irradiation. J Thorac Cardiovasc Surg. 2003;126:1198-9.

2. Bortolotti U, Scioti G, Levantino M, Milano A, Nardi C, Tartarini G. Aortic valve replacement for quadricuspid aortic valve incompetence. J Heart Valve Dis. 1998;7:515-7. doi:10.1016/j.jtcvs.2003.11.041 